\title{
Theoretical study of unloading the body of vehicles equipped with elastic partitions
}

\author{
Roman Beznosyuk*, Dmitry Ryabchikov, Sergey Borychev, Georgiy Rembalovich, and \\ Mikhail Kostenko
}

FSBEI HE RSATU, Ryazan, Russia

\begin{abstract}
For transporting potatoes, it is proposed to equip the vehicle with elastic partitions. Elastic partitions are formed by tubes of elastic material and can rotate around the axis of the transverse partition. A model has been developed that allows one to take into account a large number of parameters of root crops, a vehicle body, elastic partitions, parameters of the unloading process, and also calculate the main indicators of the efficiency of unloading root crops. As a result of optimization, it has been found that the optimal length of the elastic tube is $1.58 \mathrm{~m}$ (when the height of the vehicle body is $1.60 \mathrm{~m}$ ), the optimal coefficient of bending stiffness of the tube is $0.9 \mathrm{kN} / \mathrm{m} 2$. At the same time, the unloading time will be less than $11.5 \mathrm{~s}$ and the share of damaged root crops will be less than $4.0 \%$.
\end{abstract}

\section{Introduction}

Transport work is an important part of the production processes for growing crops. One of the operations of harvesting potatoes is the removal of the grown product from the field (it accounts for $10-12 \%$ of the total costs of the entire cultivation process of this crop) $[1,3,4$, $5]$.

Analysis of studies of the processes of on-farm transportation of potatoes in the body of a vehicle showed that one of the factors that significantly affect the level of damage to transported products is a decrease in the distance of rolling potato tubers when unloading the body $[2,6]$. To reduce damage to the transported products in the body of the vehicle, it is necessary to install elastic partitions.

\section{Materials and methods}

A vehicle with elastic partitions contains a base (1) (Fig. 1), a pair of end walls (2), a sidewall (3), a tailgate (4) in its upper part pivotally connected to end walls (2), and having the ability to be fixed in the lower part with the end walls using clamps (are not shown in the figure), an elastic partition (5) fixed on the end walls (2) and made of hollow tubes of

\footnotetext{
${ }^{*}$ Corresponding author: romario345830@yandex.ru
} 
elastic material (7), which can rotate around axis (6) of the transverse partition (5) and have different lengths, and it decreases from the center of the elastic partition to the end walls (2) symmetrically.

A vehicle with elastic partitions for transporting root and tuber crops works as follows. At the initial moment of unloading, the operator opens the locks of the tailgate (4) of the vehicle with elastic partitions for transporting root crops. First, the root crops located at the tailgate are unloaded. Then, as the vehicle with elastic partitions overturns for transporting root crops, part of the heap of root crops keeps the elastic partition (5) from displacement, excluding the avalanche-like descent of the heap of root crops. Due to less friction in the middle part of the vehicle with elastic partitions for transporting root and tuber crops, the hollow tubes (7) of the elastic partition (5), rotating around the axis (6), change the angle of inclination, which contributes to the partial unloading of root and tuber crops located behind the elastic partition (5). Gradually releasing the tubes (7) of the elastic partition (5) a heap of root crops is dosed out from the middle to the end walls (2) of the vehicle with elastic partitions for transporting root crops. The value of the tipping angle is changed gradually, focusing on the unloading speed until the base (1) is completely cleaned. The sidewall (2) of the vehicle with elastic partitions for transporting root and tuber crops together with the axis (6) creates additional rigidity when unloading. To regulate the unloading speed, hollow tubes (7) made of elastic material have different lengths, and the gap between the tube and the base depends on resistance to movement of root crops along the width of the vehicle with elastic partitions for transporting root crops.

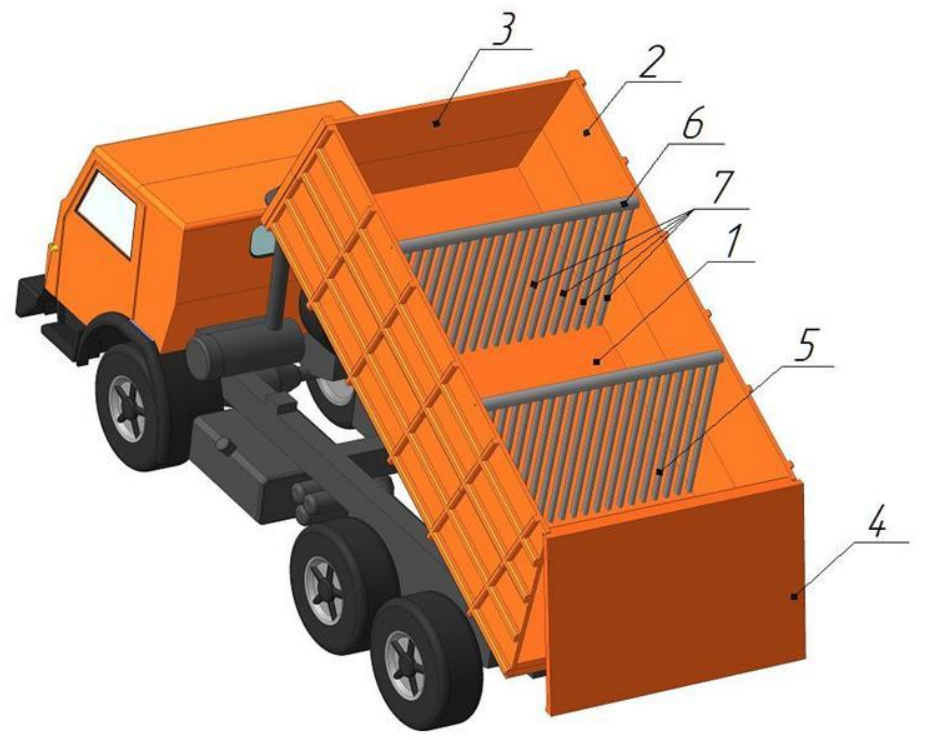

1 - base; 2 - end walls; 3 - sidewall; 4 - tailgate; 5 - elastic partition; 6 - axis; 7 - hollow tube

Fig. 1. Position of the elastic partition when unloading

A model has been developed that allows to take into consideration a large number of parameters of root crops, a vehicle body, elastic partitions, parameters of the unloading process, and also calculate the main indicators of the efficiency of unloading root crops. The relationship between the input parameters of the model and the performance indicators is shown schematically in Figure 2.

The variables related to the developed model can be divided into three groups: two groups of input variables and one group of performance indicators.

The first group of input variables include the design and technological parameters of the 
device:

$\varphi_{\mathrm{m}}$ is the maximum tilt angle of the vehicle body;

$t_{\mathrm{t}}$ is the time of tilting the vehicle body with constant angular velocity to the maximum angle $\varphi_{\mathrm{m}}$;

$c_{\mathrm{b}}$ is the bending stiffness coefficient of elastic tubes;

$n_{\mathrm{ep}}$ is the number of elastic partitions in the vehicle body.

The second group of variables sets the properties of the root crop system:

$h_{1}$ is the vehicle body loading height;

$d_{\mathrm{r}}$ is the diameter of root crops (in the version of the model with root crops of the same diameter);

$k_{\mathrm{v}}$ is the coefficient of viscous friction between root crops, which allows implicitly setting levels of contamination and stickiness of root crops.

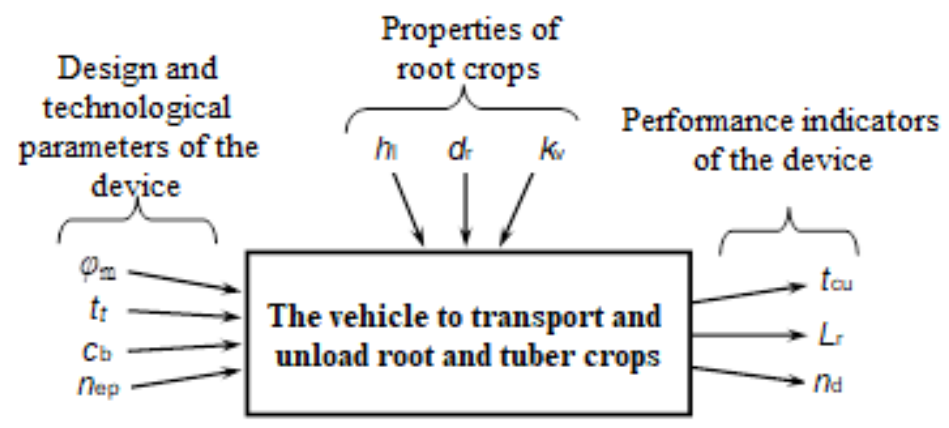

Fig. 2. Main input and output parameters of the vehicle model with elastic partitions

Performance indicators of the vehicle with elastic partitions include:

$t_{\mathrm{cu}}$ is the time of complete unloading of root and tuber crops;

$L_{\mathrm{r}}$ is the average distance of rolling out root and tuber crops;

$n_{\mathrm{d}}$ is the share of damaged roots and tubers.

Further theoretical research consists in varying the parameters of the model and studying the response of efficiency indicators of the vehicle with elastic partitions for transportation and unloading of root and tuber crops.

The influence of the maximum tilt angle of the vehicle body.

With an increase in the limit tilt angle of the vehicle body $\varphi_{m}$ the intensity of unloading increases significantly, which favorably affects the speed of unloading, but adversely affects the damage of root crops and their rolling. To study the influence of angle $\varphi_{\mathrm{m}}$ on efficiency of the unloading process, five computer experiments were carried out with a change in $\varphi_{\mathrm{m}}$ from 15 to $35^{\circ}$ at a pitch of $5^{\circ}$ (Fig. 3, 4). For comparison, computer experiments were carried out both for a vehicle body equipped with two elastic partitions (solid lines in the graphs of Figures 4-10) and for a standard vehicle body without elastic partitions (dashed lines in Figures 4-10).

\section{Results and discussion}

Determining parameters of elastic partitions.

Elastic partitions are characterized by two main parameters: length $L_{\mathrm{p}}$ and coefficient of bending stiffness $c_{\mathrm{b}}$ [7]. Let us investigate the joint influence of the parameters of elastic partitions $L_{\mathrm{p}}$ and $c_{\mathrm{b}}$ on the efficiency indicators and perform a two-factor optimization of parameters $L_{\mathrm{p}}$ and $c_{\mathrm{b}}$. Analytically, this optimization problem can be written as follows: 


$$
\left\{\begin{aligned}
t_{c u}\left(L_{p}, c_{\dot{b}}\right) & \rightarrow \min ; \\
L_{r}\left(L_{p}, c_{b}\right) \rightarrow \min ; & =L_{p}^{o p t}, \quad c_{b}^{o p t} \\
n_{d}\left(L_{p}, c_{b}\right) & \rightarrow \min ;
\end{aligned}\right.
$$

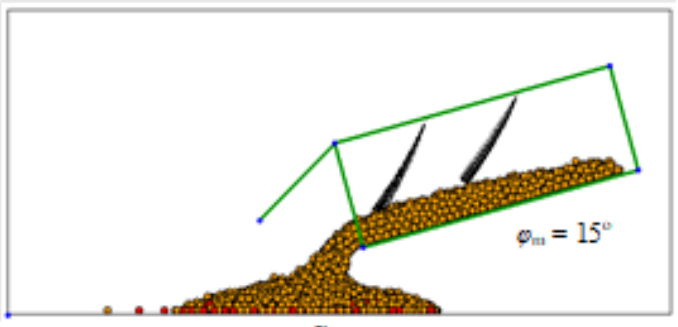

a

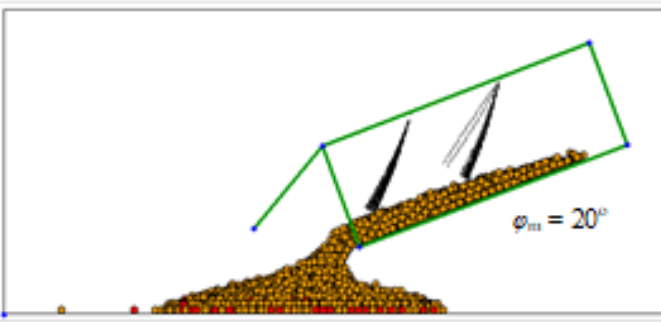

$b$

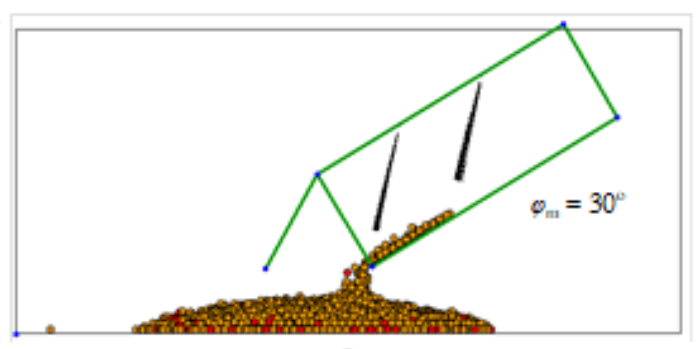

$c$

Fig. 3. The state of the system of root and tuber crops at the moment of reaching the maximum angle $\varphi_{\mathrm{m}}$ of the vehicle body tilt (at a constant angular speed of the vehicle body tilt of 4 degrees per second): $a-15^{\circ}, b-20^{\circ}, c-30^{\circ}$
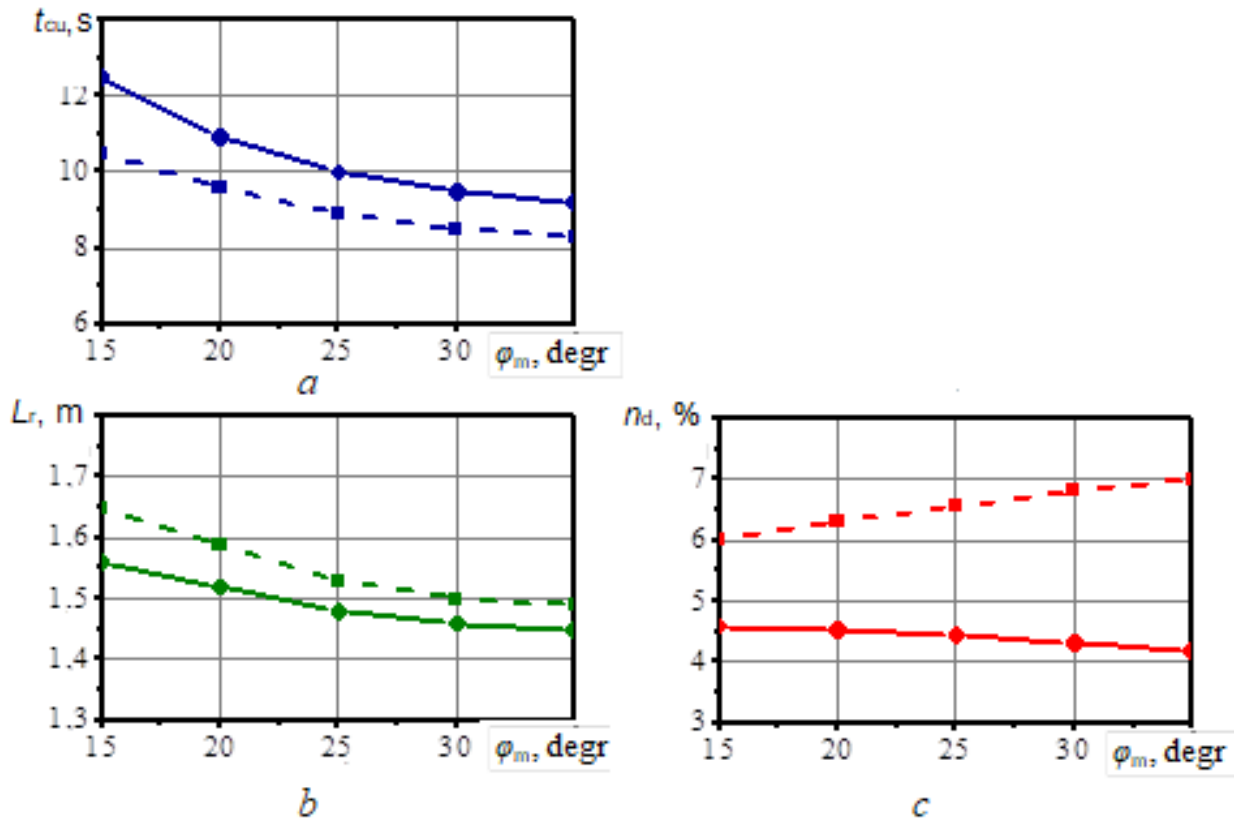

Fig. 4. Influence of the maximum tilt angle of the vehicle body $\varphi_{\mathrm{m}}$ (at a constant angular velocity of the vehicle body tilt of 4 degrees per second) on complete unloading time $t_{\mathrm{cu}}(a)$, average rolling distance $L_{\mathrm{r}}(b)$ and share of damaged root crops $n_{\mathrm{d}}(c)$. Solid and dashed lines stand for equipped and not equipped with elastic partitions, respectively 
Influence of the body tilt speed.
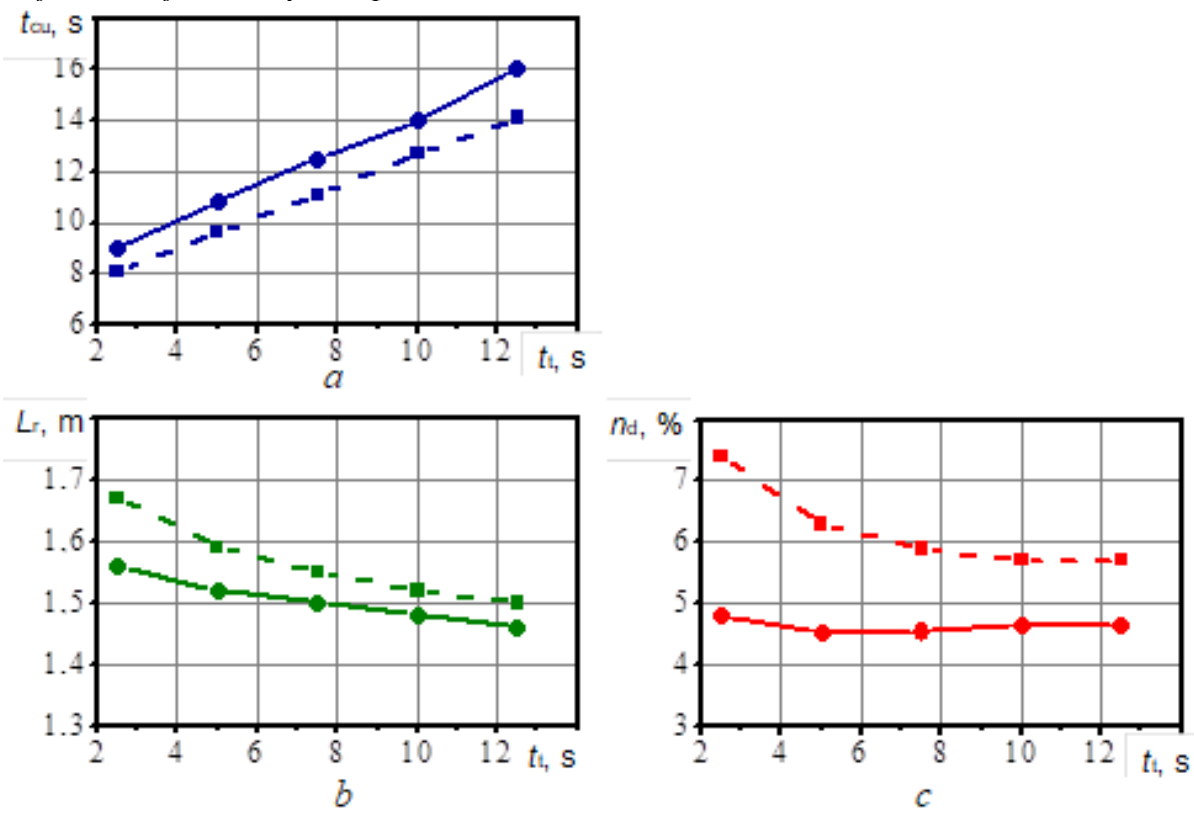

Fig. 5. Influence of time $t_{\mathrm{t}}$ of the vehicle body tilt by an angle of $20^{\circ}$ on complete unloading time $t_{\text {cu }}$ $(a)$, average rolling distance $L_{\mathrm{r}}(b)$ and share of damaged root crops $n_{\mathrm{d}}(c)$. Solid and dashed lines stand for equipped and not equipped with elastic partitions bodies, respectively

The solution to the optimization problem is to find such a region of variation of factors $L_{\mathrm{t}}$ and $c_{\mathrm{b}}$, where time of unloading $t_{\mathrm{cu}}$, rolling distance $L_{\mathrm{r}}$ and share of damaged root and tuber crops $n_{\mathrm{d}}$ will be minimal.

To solve the two-factor optimization problem, nine computer experiments were carried out, in which tube length $L_{\mathrm{t}}$ was set equal to $1.40,1.52,1.64 \mathrm{~m}$ (the vehicle body height was $1.60 \mathrm{~m}$ ) while changing bending stiffness coefficient of the tube $c_{\mathrm{b}}$ on levels of $0.6,1.0,1.4$ $\mathrm{kN} / \mathrm{m}^{2}$.

The bending stiffness coefficient has the physical meaning of the force that must be applied to ensure the deflection of $1 \mathrm{~m}$ of the tube resting on two stops with a distance of 1 $\mathrm{m}$ between the stops. In particular, a factor of $1.0 \mathrm{kN} / \mathrm{m}^{2}$ means that when a force of $10 \mathrm{~N}$ is applied (based on the mass of a conventional load of approximately $1 \mathrm{~kg}$ ), the tube deflection will be $1 \mathrm{~cm}$ if the elastic tube rests on stops with a distance of $1 \mathrm{~m}$ between them.

Figure 6 shows the state of the system for two different lengths $L_{\mathrm{t}}$ of elastic tubes at a time instant of $2.2 \mathrm{~s}$ from the beginning of the computer experiment. As can be judged from these projections, if the length of the elastic tubes is too low, they are carried away by the upper layers of root and tuber crops, and have a weak inhibitory effect on unloading (Figure $6, a)$. If the length of the elastic tubes is too long, they have a good effect on slowing down the unloading, however, they can injure the roots and tubers at the bottom of the vehicle body due to significant impact forces on them (Figure 6, $b$ ).

Based on the data set obtained as a result of nine optimization computer experiments, analytical formulas are obtained for functions $t_{\mathrm{cu}}\left(L_{\mathrm{p}}, c_{\mathrm{b}}\right), L_{\mathrm{r}}\left(L_{\mathrm{p}}, c_{\mathrm{b}}\right)$ and $n_{\mathrm{d}}\left(L_{\mathrm{p}}, c_{\mathrm{b}}\right)$. To generalize and smooth the results, each function was approximated by second-order polynomials in the form:

$$
K\left(L_{\mathrm{p}}, c_{\mathrm{b}}\right)=k_{1} L_{\mathrm{p}}^{2}+k_{2} c_{\mathrm{b}}^{2}+k_{3} L_{\mathrm{p}} \cdot c_{\mathrm{b}}+k_{4} L_{\mathrm{p}}+k_{5} c_{\mathrm{b}}+k_{6},
$$


where $K$ is optimization criterion $\left(t_{\mathrm{cu}}, L_{\mathrm{r}}\right.$ or $\left.n_{\mathrm{d}}\right) ; k_{1} \ldots k_{6}$ are polynomial parameters.

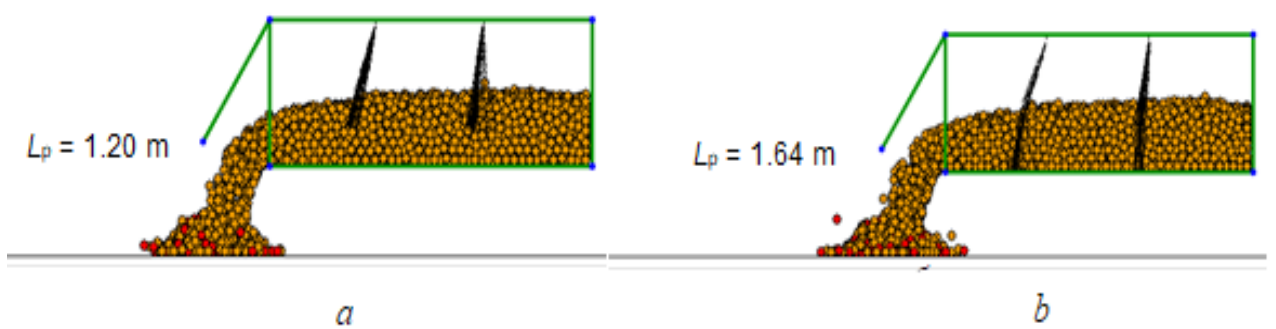

Fig. 6. The process of unloading root and tuber crops with different lengths of elastic partitions $L_{\mathrm{p}}: a$ $-1.20 \mathrm{~m}, b-1.64 \mathrm{~m}$

The parameters of the polynomials were determined by the least squares method, within which the sum of the squared deviations of the analytical dependence on the results of a computer experiment was minimized:

$$
\sum_{i=1}^{N_{C E} \sum}\left(K_{\text {analyt. }}\left(L_{p}^{i}, c_{b}^{i}\right)-K_{C E}^{i}\left(L_{p}^{i}, c_{b}^{i}\right)\right)^{2} \rightarrow \min ,
$$

where $i$ and $N_{\mathrm{CE}}$ are the serial number and the total number of computer experiments; $K_{\text {analyt. }}$ is the required analytical (polynomial) dependence of criterion $K$ on factors $h$ and $s ; K^{\mathrm{i}} \mathrm{CE}$ are values of criterion $K$, determined in the $i$-th computer experiment with parameters $h^{\mathrm{i}}$ and $s^{\mathrm{i}}$.

As a result of the approximation performed in Mathcad 14 program, the following analytical formulas for the device efficiency indicators were obtained:

$$
\begin{gathered}
t_{\mathrm{cu}}\left(L_{\mathrm{p}}, c_{\mathrm{b}}\right)=1.157 L_{\mathrm{p}}^{2}+0.104 c_{\mathrm{b}}^{2}+2.604 L_{\mathrm{p}} \cdot c_{\mathrm{b}}+3.183 L_{\mathrm{p}}-4.125 c_{\mathrm{b}}+3.439 \\
L_{\mathrm{r}}\left(L_{\mathrm{p}}, c_{\mathrm{b}}\right)=-0.116 L_{\mathrm{p}}^{2}-0.010 c_{\mathrm{b}}{ }^{2}-0.365 L_{\mathrm{p}} \cdot c_{\mathrm{b}}+0.147 L_{\mathrm{p}}+0.487 c_{\mathrm{b}}+1.642 \\
n_{\mathrm{d}}\left(L_{\mathrm{p}}, c_{\mathrm{b}}\right)=35.88 L_{\mathrm{p}}{ }^{2}+0.729 c_{\mathrm{b}}{ }^{2}+8.333 L_{\mathrm{p}} \cdot c_{\mathrm{b}}-126.7 L_{\mathrm{p}}-12.75 c_{\mathrm{b}}+113.6
\end{gathered}
$$

where $L_{\mathrm{p}}$ is measured in meters, $c_{\mathrm{b}}$ is measured in kilonewtons per square meter $\left(\mathrm{kN} / \mathrm{m}^{2}\right), t_{\mathrm{cu}}$ is measured in seconds, $L_{\mathrm{r}}$ is measured in meters; $n_{\mathrm{d}}-$ is measured in percentage.

The resulting formulas can be used for quick evaluation (without performing real or computer experiments) of the performance indicators of the device depending on parameters of elastic tubes.

For further analysis, functions $t_{\mathrm{cu}}\left(L_{\mathrm{p}}, c_{\mathrm{b}}\right), L_{\mathrm{r}}\left(L_{\mathrm{p}}, c_{\mathrm{b}}\right)$ and $n_{\mathrm{d}}\left(L_{\mathrm{p}}, c_{\mathrm{b}}\right)$ are presented in the form of graphs (Figure 7) and cartograms (Figure 8). The graphs make it possible to analyze the nature of the response surfaces visually: dependences $t_{\mathrm{cu}}\left(L_{\mathrm{p}}, c_{\mathrm{b}}\right), L_{\mathrm{r}}\left(L_{\mathrm{p}}, c_{\mathrm{b}}\right)$ are close to linear ones, while dependence $n_{\mathrm{d}}\left(L_{\mathrm{p}}, c_{\mathrm{b}}\right)$ is substantially nonlinear and has a concave character. Cartograms are intended for quantitative analysis and represent a top view of the graphs, depicting the response surface with level lines.

An example of using cartograms is shown in Figure 8, a. If the length of the elastic tube is $1.45 \mathrm{~m}$ (point A) and the bending stiffness coefficient is $1.0 \mathrm{kN} / \mathrm{m}^{2}$ (point $B$ ), then the corresponding point of factor space $C$ falls approximately halfway between the level lines $t_{\mathrm{cu}}=10.0 \mathrm{~s}$ and $t_{\mathrm{cu}}=10.5 \mathrm{~s}$. That is, the unloading time will be $10.25 \mathrm{~s}$. 


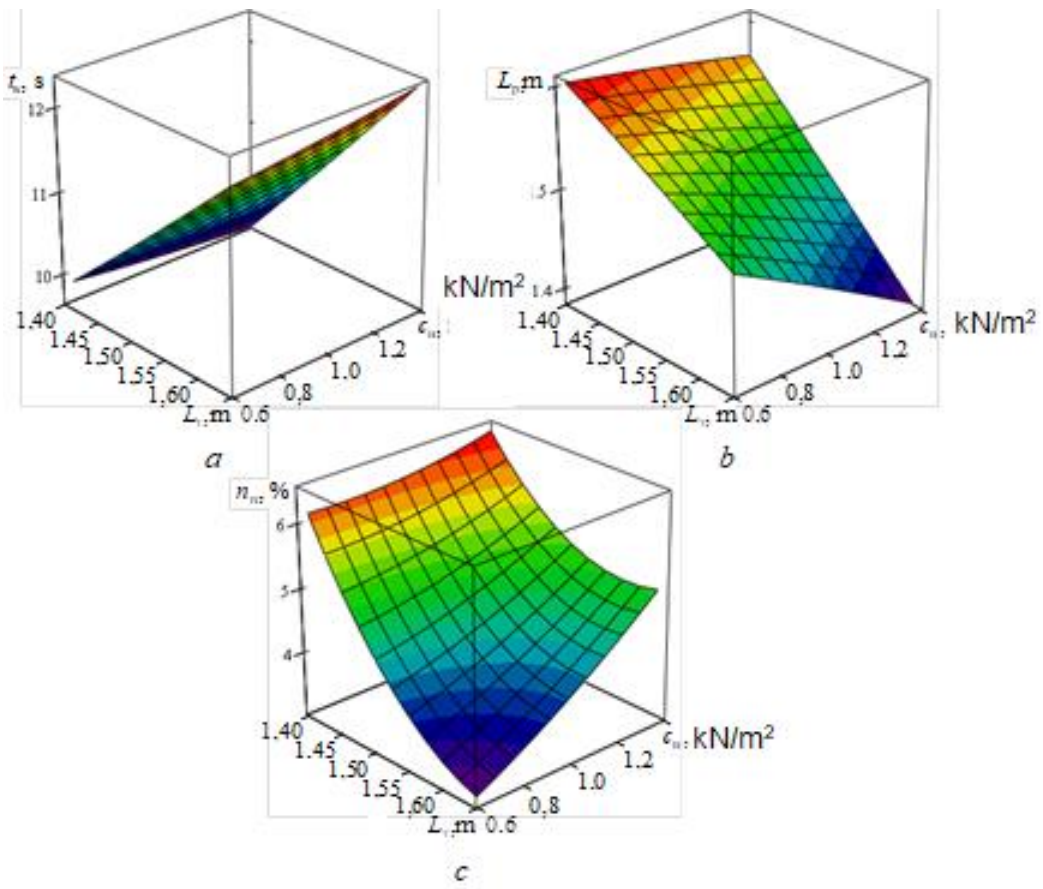

Fig. 7. Graphs of the influence of length $L_{\mathrm{p}}$ and coefficient of bending stiffness $c_{\mathrm{b}}$ of elastic partitions on unloading time $\mathrm{t}_{\mathrm{cu}}(a)$, rolling distance $L_{\mathrm{r}}(\mathrm{b})$ and share of damaged root crops $n_{\mathrm{d}}(c)$
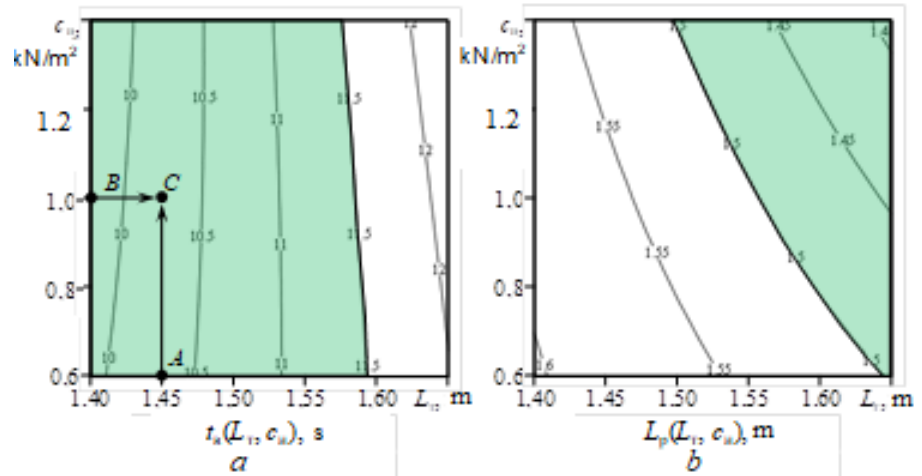

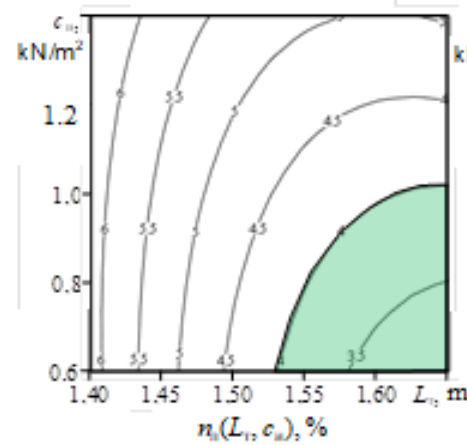

$c$

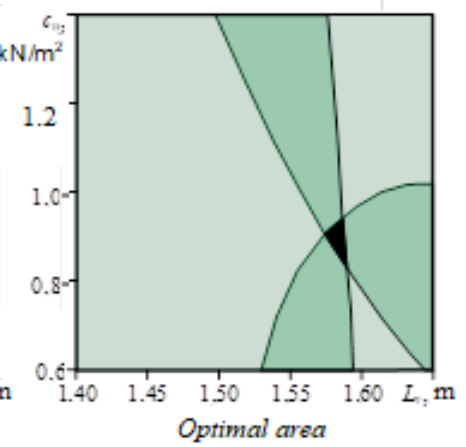

d

Fig. 8. Optimization cartograms of elastic partition parameters (Favorable areas of factor space are shaded. The general optimal area is highlighted in black) 
Areas of favorable (minimum) values of indicators are shaded on cartograms. The threshold values for dividing into favorable and unfavorable areas were chosen $t_{\mathrm{cu}}=11.5 \mathrm{~s}$ (Figure $8, a$ ), $L_{\mathrm{r}}=1.50 \mathrm{~m}$ (Figure $8, b$ ) and $n_{\mathrm{d}}=4 \%$ (Figure $8, c$ ). The choice was made proceeding from the conditions that the favorable area will occupy a significant fraction of the factor space, include the smallest values of the criterion, and the area border will be a level line on the cartogram.

The intersection of favorable areas (Figure 8, d) is an optimal area, which simultaneously takes into consideration the requirements for low values of unloading time, rolling distance and the share of damaged root and tuber crops.

By the location of the optimal area in the factor space (Figure 8, d), the following conclusion can be drawn. The optimal length of the elastic partition is $1.58 \mathrm{~m}$ (at a vehicle body height of $1.60 \mathrm{~m}$, that is, the clearance between the partition and the bottom of the vehicle body should be $2 \mathrm{~cm}$ ), the optimum bending stiffness coefficient of the tube is 0.9 $\mathrm{kN} / \mathrm{m}^{2}$. At the same time, the unloading time will be less than $11.5 \mathrm{~s}$, the rolling distance of root and tuber crops will be less than $1.50 \mathrm{~m}$, and the share of damaged root and tuber crops will be less than $4.0 \%$. For the obtained optimal parameters, a separate computer experiment was carried out, which confirmed that the efficiency indicators of the device did not exceed the indicated values.

Table 1. Influence of the number of rows of elastic partitions $n_{\mathrm{pr}}$ on unloading time $t_{\mathrm{cu}}$, average rolling distance $L_{\mathrm{r}}$ and proportion of damaged root and tuber crops $n_{\mathrm{d}}$

\begin{tabular}{|c|c|c|c|}
\hline$n_{p r}$ & $t_{c u}, s$ & $L_{r}, m$ & $n_{d}, \%$ \\
\hline Without elastic partitions & 9.7 & 1.60 & 6.3 \\
\hline 1 row & 10.4 & 1.56 & 5.4 \\
\hline 2 rows & 11.0 & 1.52 & 4.6 \\
\hline 3 rows & 11.4 & 1.47 & 3.8 \\
\hline
\end{tabular}

Influence of the number of elastic partitions.

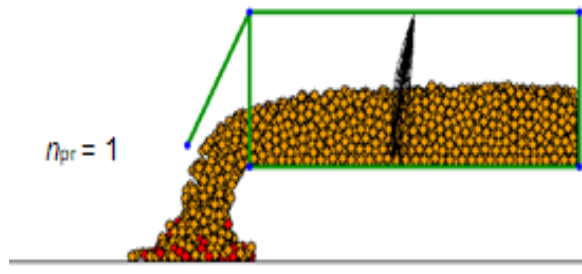

$a$

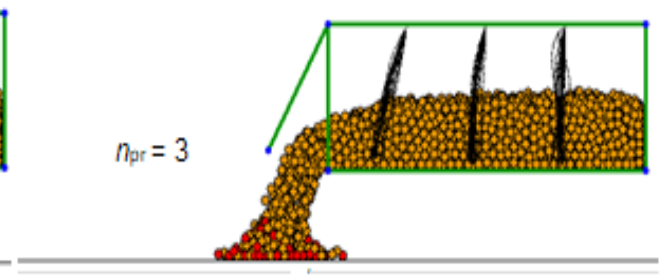

$b$

Fig. 9. The process of unloading root and tuber crops with a different number of elastic partitions $n_{\mathrm{pr}}$ : $a-1$ row, $b-3$ rows

Influence of the loading height of the vehicle body.

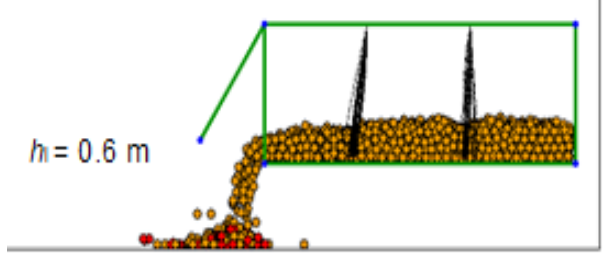

a

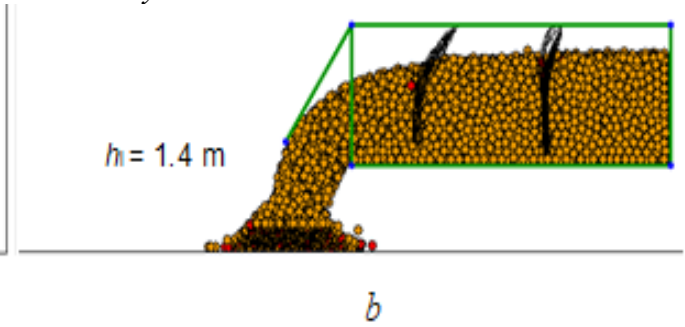

Fig. 10. The process of unloading root and tuber crops at different initial loading height of the vehicle body $h$ : $a-0.6 \mathrm{~m}, b-1.4 \mathrm{~m}$ 


\section{Conclusion}

A mathematical model of a device for transporting and unloading root crops was developed, taking into consideration the physical properties of root crops, physical and geometric characteristics of the vehicle body and elastic partitions, as well as the parameters of the unloading process. The model allows evaluating the effect of equipping the vehicle body with rows of elastic partitions and determining their optimal parameters. As a result, it was found that the rational clearance between elastic partitions and the bottom of the vehicle body was $2 \mathrm{~cm}$, and the bending stiffness coefficient of the elastic tubes was $0.9 \mathrm{kN} / \mathrm{m}^{2}$. At the same time, the unloading time will be less than $11.5 \mathrm{~s}$, the rolling distance of root and tuber crops will be less than $1.50 \mathrm{~m}$ and the share of damaged root crops will be less than $4.0 \%$.

\section{References}

1. N.V. Byshov, S.N. Borychev, I.A. Uspensky, I.A. Yukhin, A.A. Golikov, O.V. Filyushin, IOP Conference Series: Earth and Environmental Science, 341(1), 012145 (2019)

2. I.A. Uspensky, G.K. Rembalovich, I.A. Yukhin, D.S. Ryabchikov, A.S. Stepashkina, IOP Conference Series: Materials Science and Engineering, 832(1), 012059

3. N.I. Vereschagin, V.V. Zubkov, S.S. Tubolev, Modern machine technologies for potato production, Technics and equipment for the village, 7, (2009)

4. I.A. Uspensky, A.A. Simdyankin, I.A. Yukhin, O.V. Filyushin, Innovative development of the modern agro-industrial complex of Russia, Materials of the national scientific-practical conference, Ryazan, 202 (2016)

5. N.V.Anikin, Increasing the efficiency of potato transportation by improving the tractor transport unit, Diss., Ryazan (2006)

6. N.I. Vereschagin, Bulletin of FSEI HPO MGAU, 3, 69 (2007)

7. Yu.N. Grigoryev, V.A. Vshivkov, M.P. Fedoruk, Numerical simulation by particle-incell methods (2004) 